\title{
The Effectiveness of Neurofeedback Therapy in Craving of Methamphetamine Use
}

\author{
Peyman Hashemian \\ Psychiatry and Behavioral Sciences Research Center, Ibn-e-Sina Hospital, Faculty of Medicine, Mashhad \\ University of Medical Sciences, Mashhad, Iran \\ Email: hashemianp@mums.ac.ir
}

Received 5 March 2015; accepted 29 March 2015; published 3 April 2015

Copyright (C) 2015 by author and Scientific Research Publishing Inc.

This work is licensed under the Creative Commons Attribution International License (CC BY). http://creativecommons.org/licenses/by/4.0/

(c) (i) Open Access

\begin{abstract}
Introduction: Relapse in methamphetamine dependency is one of the most difficult parts to treat. Therefore treatment of craving for usage is one of the essential sections of treatment in methamphetamine dependency (addiction). This study evaluates the effect of neurofeedback therapy on craving for use. Methods: In this study 20 male patient with methamphetamine dependency who diagnosed on the basis of DSM-V were selected. None of the patients had any psychiatric and neurologic disorder except addiction of methamphetamine. Patients were divided into 2 groups of 10. The first group has taken real neurofeedback therapy sessions while the second has undergone non-real neurofeedback (sham) therapy. Then the two groups have been compared with $t$-test. Result: The result shows that in the first group (real neurofeedback), craving for methamphetamine use has been decreased significantly whereas in the second group (non-real or sham), the decrease was not significant. Conclusion: Neurofeedback therapy is effective in treatment of craving for methamphetamine use.
\end{abstract}

\section{Keywords}

Methamphetamine, Neurofeedback, Craving

\section{Introduction}

There are many studies showing the effectiveness of neurofeedback therapy in the remission of alcohol and substance dependency [1]-[6].

Passini and colleagues (1977) [7], Fahrion and his team (1992) [8], and Peniston and Saxby (1995) [9] concluded that neurofeedback therapy was effective in alcoholic patient.

Goldberg and colleagues [10] in 1976 showed the effect of neurofeedback therapy (alpha conditioning) on patients with methadone dependency. 
In 1989, Peniston and Kulkosky [11] showed similar result in patients with alcohol dependency.

Kelley (1997) [12] and Kaiser and colleagues (1999) [13] evaluated the effect of alpha/theta training in alcoholic patient within a 9-month period and resulted in marked decrease of relapse. Bodehnamer and Callaway [14] have extended the follow-up of peniston protocol result in 2003. Raymond and colleagues [15] in 2005 showed more avoidance and remission in patients who took neurofeedback therapy sessions. Several studies have been done on alpha/theta protocol on $\mathrm{P}_{\mathrm{z}}$ or $\mathrm{P}_{4}$ [15] [16].

The objective of this study is to find out the effect of neurofeedback therapy on methamphetamine craving on $\mathrm{P}_{\mathrm{z}}$ region.

\section{Method}

This study is clinical trial with 20 male patients who were referred to Ebne-Sina Hospital in Mashhad, Iran. They were selected by psychiatrist using convenience sampling and then divided into two groups of 10 after matching age and IQ. The first group consisting of 10 has undergone real neurofeedback therapy and the second group has undergone non-real neurofeedback therapy (sham). Each patient took 10 sessions of 30 minutes neurofeedback therapy. Theta/Alpha enhancement has been done on $\mathrm{P}_{\mathrm{z}}$ region with protocol of unipolar in the two groups. DDQ (Desire for drug questionnaire) is used for measurement of craving [17]. Validity and reliability of this questionnaire have been checked in Iranian population [18] [19].

Paired t-test was used to compare data using SPSS software, version 20.

\section{Result}

The following table shows the descriptive statistical analysis of change in craving in the two groups (Table 1).

The difference between pre-test to post-test within each group were measured and compared with paired ttest (Table 2).

As seen in Table 2, the craving for methamphetamine use from $1^{\text {st }}$ session to $10^{\text {th }}$ session was significantly decreased in real neurofeedback group ( $\mathrm{p}<0.005$ ), whereas the decrease was not significant in non-real group.

\section{Discussion}

This study shows that theta/alpha enhancement (Deep Relaxation) in $\mathrm{P}_{\mathrm{z}}$ region significantly reduces craving for use of methamphetamine.

This study shows the positive effect of neurofeedback therapy in craving for methamphetamine use as it was for other substance or alcohol use in other researches [1]-[15].

\section{Conclusion}

Theta/Alpha enhancement protocol (Deep Relaxation) in neurofeedback therapy in $\mathrm{P}_{\mathrm{z}}$ region is an effective method for treatment of Methamphetamine craving.

\section{Table 1. Descriptive statistical analysis of change in craving in each group.}

\begin{tabular}{cccccccccccccccc}
\hline & \multicolumn{3}{c}{ Max } & \multicolumn{3}{c}{ Min } & \multicolumn{3}{c}{ SE } & & SD & Mean \\
Craving & Post & Pre & Post & Pre & Post & Pre & Post & Pre & Post & Pre \\
\hline Case group & 55 & 69 & 21 & 36 & 3.6363 & 3.76372 & 11.499 & 11.9019 & 36.70 & 52.10 \\
Control group & 63 & 68 & 31 & 40 & 3.4583 & 3.4649 & 10.936 & 10.9569 & 49.40 & 52.50 \\
\hline
\end{tabular}

Table 2. Comparison of craving between the two groups.

\begin{tabular}{ccc}
\hline \multirow{2}{*}{ Paired Sample t-Test } & Pre/Post-Test \\
\cline { 2 - 3 } $\mathrm{t}$ & Real Neurofeedback Group & Non-Real Neurofeedback Group (Sham) \\
p-value & 3.774 & 1.491 \\
\hline
\end{tabular}




\section{Suggestion}

This study has been performed on male patients. Researches on female subjects and their comparison are suggested.

\section{References}

[1] Hammond, D.C. (2006) What Is Neurofeedback: An Update. University of Utah School of Medicine, Salt Lake City.

[2] Sokhadze, T.M., Cannon, R.L. and Trudeau, D.L. (2008) EEG Biofeedback as a Treatment for Substance Use Disorders: Review, Rating of Efficacy, and Recommendations for Further Research. Applied Psychophysiology and Biofeedback, 33, 1-28. http://dx.doi.org/10.1007/s10484-007-9047-5

[3] Sokhadze, T.M., Stewart, C.M. and Hollifield, M.H. (2007) Integrating Cognitive Neuroscience Research and Cognitive Behavioral Treatment with Neurofeedback Therapy in Drug Addiction Comorbid with Posttraumatic Stress Disorder: A Conceptual Review. Journal of Neurotherapy, 11, 13-44. http://dx.doi.org/10.1300/J184v11n02_03

[4] Scott, W.C., Kaiser, D., Othmer, S. and Sideroff, S.I. (2005) Effects of an EEG Biofeedback Protocol on a Mixed Substance Abusing Population. The American Journal of Drug and Alcohol Absue, 31, 455-469. http://dx.doi.org/10.1081/ADA-200056807

[5] Frederick, J.A., Timmermann, D.L., Russell, H.L. and Lubar, J.F. (2005) EEG Coherence Effects of Audio-Visual Stimulation (AVS) at Dominant and Twice Dominant Alpha Frequency. Journal of Neurotherapy, 8, $25-42$. http://dx.doi.org/10.1300/J184v08n04_03

[6] Masterpasqua, F. and Healey, K.N. (2003) Neurofeedback in Psychological Practice. Professional Psychology: Research and Practice, 34, 652-656. http://dx.doi.org/10.1037/0735-7028.34.6.652

[7] Passini, F.T., Watson, C.G., Dehnel, L., Herder, J. and Watkins, B. (1977) Alpha Wave Biofeedback Training Therapy in Alcoholics. Journal of Clinical Psychology, 33, 292-299. http://dx.doi.org/10.1002/1097-4679(197701)33:1+<292::AID-JCLP2270330166>3.0.CO;2-L

[8] Fahrion, S.L., Walters, E.D., Coyne, L. and Allen, T. (1992) Alteration in EEG Amplitude, Personality Factors and Brain Electrical Mapping after Alpha-Theta Training: A Controlled Case Study of an Alcoholic Recovery. Alcoholism: Clinical Experimental Research, 16, 547-551. http://dx.doi.org/10.1111/j.1530-0277.1992.tb01415.x

[9] Peniston, E.G. and Saxby, E. (1995) Alpha-Theta Brainwave Neurofeedback Training: An Effective Treatment for Male and Female Alcoholic with Depressive Symptoms. Journal of clinical psychology, 51, 685-693. http://dx.doi.org/10.1002/1097-4679(199509)51:5<685::AID-JCLP2270510514>3.0.CO;2-K

[10] Goldberg, R.J., Greenwood, J.C. and Taintor, Z. (1976) Alpha Conditioning as an Adjust Treatment for Drug Dependence. International Journal of Addiction, 11, 1085-1089.

[11] Peniston, E.G. and Kulkosky, P.J. (1989) Alpha-Theta Brain Wave Training and Beta-Endorphin Levels in Alcoholics. Clinical and Experimental Research, 13, 271-279. http://dx.doi.org/10.1111/j.1530-0277.1989.tb00325.x

[12] Kelley, M.J. (1997) Native Americans, Neurofeedback, and Substance Abuse Theory: Three Year Outcome of Alpha/Theta Neurofeedback Training in the Treatment of Problem Drinking among Dine' (Navajo) People. Nation Department of Behavioral Health, Window Rock.

[13] Kaiser, D.A., Othmer, S. and Scott, B. (1999) Effect of Neurofeedback on Chemical Dependency Treatment. Biofeedback Learning Center Journal, 15, 174-189.

[14] Bodehnamer, D.E. and Callaway, T. (2003) Extended Follow-Up of Peniston Protocol Results with Chemical Dependency. Journal of Neurotherapy, 8, 135.

[15] Raymond, J., Varney, C., Parkinson, L.A. and Gruzelier, J.H. (2005) The Effect of Alpha/Theta Neurofeedback on Personality and Mood. Cognitive Brain Research, 23, 287-292. http://dx.doi.org/10.1016/j.cogbrainres.2004.10.023

[16] Batty, M.J., Bonnington, S., Tang, B.K., Hawken, M.B. and Gruzelier, J.H. (2006) Relaxation Strategies and Enhancement of Hypnotic Susceptibility: EEG Neurofeedback, Progressive Muscle Relaxation and Self-Hypnosis. Brain Research Bulletin, 71, 83-90. http://dx.doi.org/10.1016/j.brainresbull.2006.08.005

[17] Franken, I.H.A., Hendriks, V.M. and Brink, W.V. (2002) Initial Validation of Two Opiate Craving Questionnaires. The Obsessive Compulsive Drug Use Scale and the Desires for Drug Questionnaire. Addictive Behaviors, 27, 675-685. http://dx.doi.org/10.1016/S0306-4603(01)00201-5

[18] Ekhtiari, H., Alam-Mehrjerdi, Z. and Hasani-Abharian, P. (2010) Examination and Evaluation of Craving-Inductive Verbal Cues among Persian-Speaking Methamphetamine Abusers. Journal of Advances in Cognitive Sciences, 12, 69-82. (In Persian)

[19] Ekhtiari, H., Edalati, H. and Behzadi, A. (2008) Designing and Evaluation of Reliability and Validity of Five Visual CueInduced Craving Tasks for Different Groups of Opiate Abusers. Iranian Journal of Psychiatry and Clinical Psychology, 14, 337-349. (In Persian) 